\title{
Mucocele in the Anterior Ventral Surface of the Tongue - A Rare Case report
}

\section{Basavaraj T Bhagawati ${ }^{1 *}$, Nishant Kumar ${ }^{2}$, Kumari Jyotsana ${ }^{3}$, Samreen Jaral ${ }^{4}$ and Sharanamma Bhagawati ${ }^{5}$}

${ }^{1}$ Professor and Head, Department of Oral Medicine and Radiology, Surendera

Dental College and Research Institute, India

${ }^{2}$ Reader, Department of Oral Medicine and Radiology, Surendera Dental College

and Research Institute, India

${ }^{3} \mathrm{PG}$ Student, Department of Pedodontics and Preventive Dentistry, Surendera

Dental College and Research Institute, India

${ }^{4} P G$ Student, Department of Oral Medicine and Radiology, Surendera Dental

College and Research Institute, India

${ }^{5}$ Professor, Department of Periodontics, Hazaribag College of Dental Sciences and

Hospital, Jharkhand

*Corresponding Author: Basavaraj T Bhagawati, Professor and Head, Department of Oral Medicine and Radiology, Surendera Dental College and Research Institute, India.
Received: October 19, 2021

Published: November 16, 2021

(C) All rights are reserved by Basavaraj T

Bhagawati., et al.

\begin{abstract}
Mucoceles are common cystic lesions in the oral cavity. It may occur in different locations in the oral mucosa due to trauma or obstruction of minor salivary gland ducts with the lower lip as the predominant site followed by the floor of the mouth, with buccal mucosa being the next most frequent site. However, mucoceles located on the ventral surface of the tongue originating from the anterior lingual salivary glands are extremely rare and often overlooked during screening procedures because of their asymptomatic nature. Here, we report an interesting case of mucocele in the anterior ventral surface of the tongue in a seven year old male patient The literature review outlines the various types of mucocele, its epidemiology, pathogenesis, differential diagnosis and the various treatment modalities.
\end{abstract}

Keywords: Mucocele; Cyst; MRI

\section{Introduction}

Mucoceles are benign cystic lesions of the oral cavity, which develop from the extravasation or retention of mucin produced by the minor salivary glands [1].

The mechanisms for the development of these lesions are two, mucus extravasation and mucus retention. The former is the primary cause of mucocele formation involving accessory salivary glands as a result of a physical trauma. The fluid from the ruptured ducts or acni leaks and accumulates into the adjacent tissue leading to swelling. The resulting pool of glandular secretion is first surrounded by inflammatory cells and later by reactive granulation tissue consisting of fibroblasts as a result of an immune response [2].
Mucoceles of the lower lip are the most common (77.9\%), followed by lingual mucoceles (36\%) and mucoceles of the floor of the mouth (15.6) (Jinbu., et al. 2003). Mucoceles on the ventral surface of the tongue are derived from the Blandin Nuhn glands and are considered quite unusual [3].

\section{Case Report}

A 7year old male patient reported to the Surendera Dental College and Research Institute, Sri-ganganagar with the chief complaint of swelling on the ventral surface of the tongue since two month (Figure 1).

History revealed that the patient had been aware of the swelling for approximately 2 months but denied any episodic increase or 
reduction in size. No history of any pain, trauma or systemic rise in temperature. No difficulty in speaking and chewing food. Dental history revealed that the patient visited local dentist 1 month back and referred here for further treatment. Medical history was noncontributory.

Extra-oral examination was non contributory (Figure 1, 2 and 3). On intraoral examination, the swelling was round to oval in shape, measuring approximately $1 \mathrm{X} 2 \mathrm{~cm}$ in dimension with no evidence of any discharge from the swelling. There was no visible pulsation. On palpation swelling was fluctuant and non-tender (Figure 4).

Based on history and clinical examination a provisional diagnosis of mucocele was made. Patient was subjected to transillumination test which was positive (Figure 5). Magnetic Resonance Imaging (MRI) was done and it shows well-defined round to oval cystic lesion along ventral surface of anterior tongue slightly to left of midline projecting along floor of mouth measuring 17X16X18 $\mathrm{mm}\left(\mathrm{AP}^{*} \mathrm{TR}^{*} \mathrm{CC}\right)$ figure 6 with no involvement of extrinsic muscle of tongue suggestive of Benign Cystic lesion.

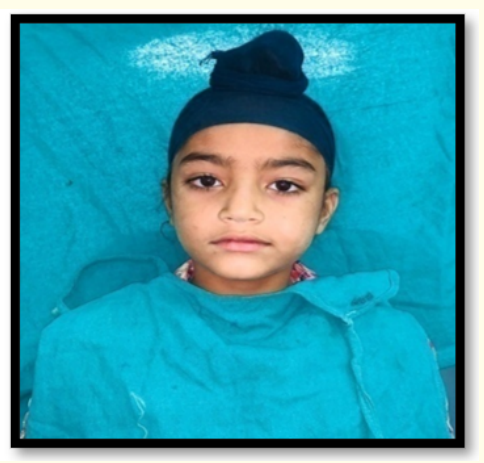

Figure 1: Extraoral view (front profile).

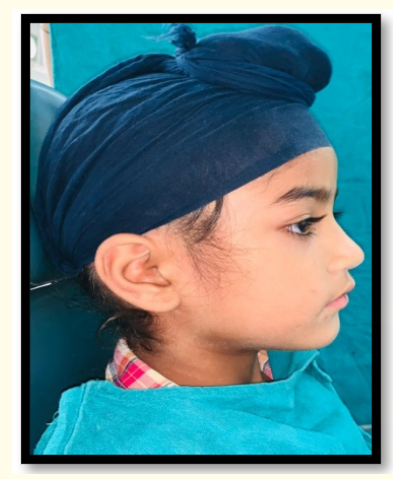

Figure 2: Extraoral view (right sided).

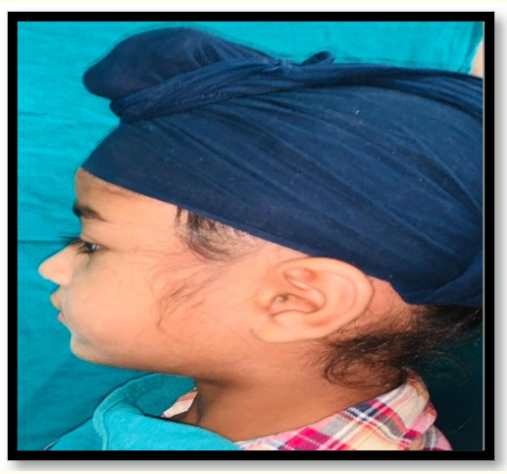

Figure 3: Extraoral view (left sided).

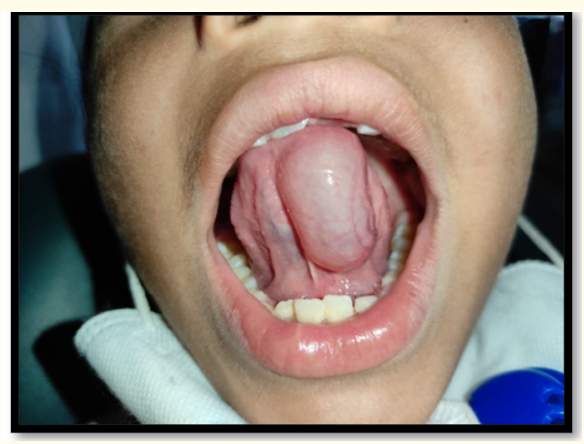

Figure 4: Intraoral examination showing fluid-filled, soft, solitary dome shaped swelling on the anterior ventral surface of the tongue.

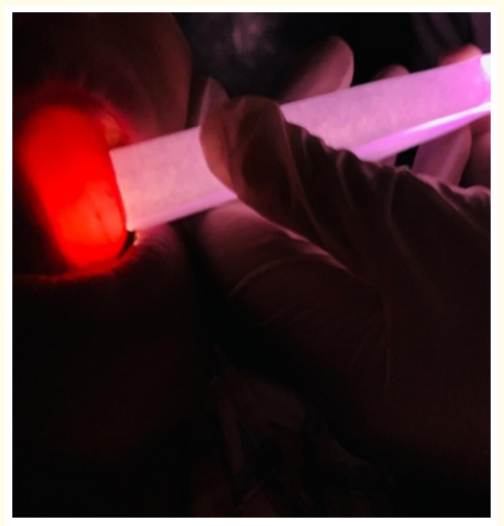

Figure 5: Transillumination test (positive).

Based upon history, clinical examination and MRI findings diagnosis of mucocele on ventral surface of tongue was made. Surgical excision was planned with scalpel with wide excision of the cyst 


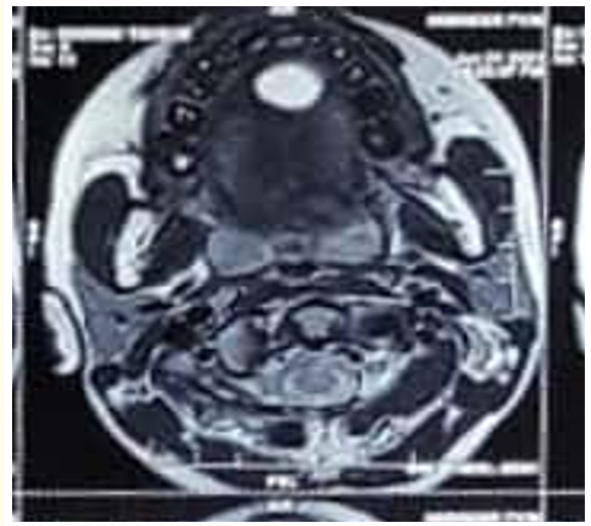

(a)

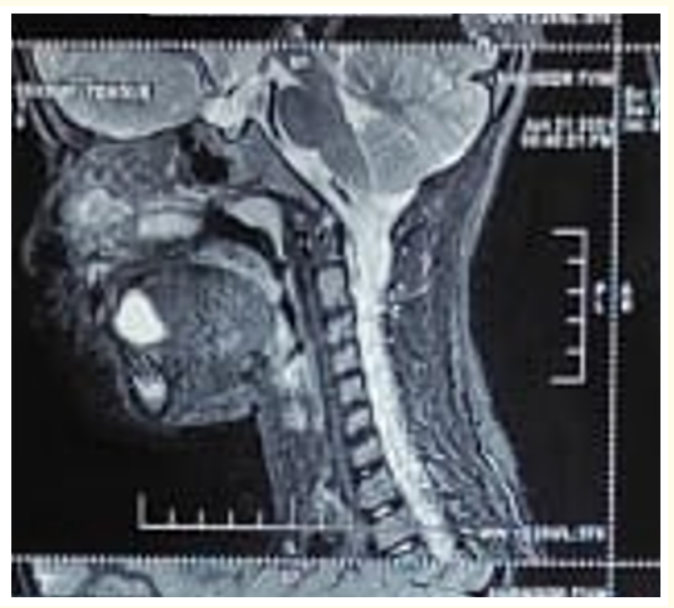

(b)

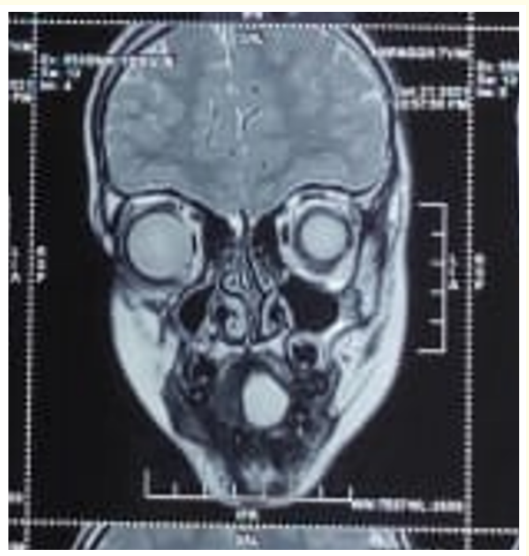

(c)

Figure 6: Magnetic Resonance Imaging of Mucocele (MRI) (a) Axial, (b) Sagittal and (c) Coronal section. under LA and IV sedation. The procedure was initiated by administration of topical anesthesia (xylocaine $5 \%$ ) to the area, followed by infiltration anesthesia (lidocaine $2 \%$ ) next to the base of the lesion and IV midazola sedation $0.05-0.1 \mathrm{mg} / \mathrm{kg}$ IV $3 \mathrm{~min}$ before procedure; not to exceeding a total cumulative dose of $0.4 \mathrm{mg} / \mathrm{kg}$ or $6 \mathrm{mg}$. The lesion was clamped with the aid of mosquito forceps and the mucocele was enucleated with an incision at the base encompassing the minor glands involved. The wound was sutured using absorbable thread and simple interrupted stitches. Analgesic medication was prescribed and advice was given regarding postoperative care. Patient was kept soft and liquid diet. SYP. Polyclave $457 \mathrm{mg}$ twice daily.

Tab. Revogesic SP $1 / 21 / 2$ - twice daily. Dentomte Gargle X 7 days. Patient was reviewed after 7 days with no complication.

\section{Review Literature}

Mucoceles are one of the most common benign soft tissue masses that occur in the oral cavity. Mucoceles (muco - mucus and coele - cavity) by definition are cavities filled with mucus [4]. All cystic lesions of the minor salivary glands, collectively and clinically referred to as mucoceles, are described as either the extravasation type or the retention type. The term mucus extravasation phenomenon (or escape reaction) is used when mucus has been extruded into the connective tissue and is surrounded by a granulation tissue envelope. The term mucus retention cyst is used to describe a cyst with retained mucin, which is lined by ductal epithelium [5].

Mucoceles most frequently appear on the lip, especially the lower lip, since it can get injured easily, followed by the floor of the mouth, the ventral tongue and the buccal mucosa. ${ }^{6}$ Standish and Shafer [7] reported that nearly $45 \%$ of the mucoceles occurred on the lower lip and they are less frequently observed on the anterior ventral surface of the tongue where the Blandin-Nuhnseromucous salivary glands exist, in close proximity to the lingual tonsils, the glands of Weber and finally in the periphery of circumvallate papillae and the base of the clefts between the foliate papillae and the serous salivary glands of von Ebner. Pathologies of the oral cavity tend to show the greatest predilection in children, of which salivary gland pathology is most commonly occurring with a percentage of 87.5\% of mucous extravasation cysts [8]. Despite numerous reports of mucoceles originating on the ventral surface of the tongue, there have been only scarce reports of such a cyst forming on the dorsal surface. This article describes a mucous extravasation cyst developed on the ventral tongue of a male. 


\section{Conclusion}

The case presented here indicates that mucocele can involve the unusual location like ventral surface of tongue. This emphasizes the need for a vigilant approach when clinicians encounter soft tissue swellings in the maxillofacial region. Their clinical appearance is unique, with longitudinal swelling in the ventral surface of the tongue parallel to the lingual frenulum. Advanced imaging like ultrasound, CT, MRI, or needle aspiration can confirm the diagnosis but are not always necessary, as the diagnosis is clinically obvious.

\section{Bibliography}

1. Nagar SR., et al. "Mucocele of the tongue: A case report and review of literature". Journal of Oral and Maxillofacial Pathology 25 (2021): 37-41.

2. Khalekar YJ., et al. "Mucocele of tongue: A rare case report". Journal of Indian Academy of Oral Medicine and Radiology 28 (2016): 462-464.

3. More CB., et al. "Oral mucocele: A clinical and istopathological study". Journal of Oral and Maxillofacial Pathology 18 (2014): 727-730.

4. Shamim T. "Oral mucocele (mucous extravasation cyst)". Journal of Ayub Medical College Abbottabad 21 (2009): 169-172.

5. Jani DR., et al. "Mucocele - a study of 36 cases". Indian Journal of Dental Research 21 (2010): 337-340.

6. Karthikeyan M., et al. "Mucocele: A diagnostic dilemma!!" Journal of Pharmacy and Bioallied Sciences 8 (2016): 168-170.

7. Nicolai P., et al. "Sphenoid mucocele with intracranial invasion secondary to nasopharyngeal acinic cell carcinoma". Head and Neck 13 (1991): 540-544.

8. Pasquier B., et al. "Orbital mucocele". Journal Français D’Ophtalmologie 17 (1994): 608-613.

\section{Volume 5 Issue 12 December 2021}

(C) All rights are reserved by Basavaraj T Bhagawati., et

al. 